\title{
Usos ideológicos de elementos prestados del euskera en la creación de palabras en español en el lenguaje periodístico
}

\author{
María del Carmen Méndez Santos \\ Universitat d'Alacant \\ Área de Lingüistica General \\ Campus de San Vicente del Raspeig, s/n \\ 03690 San Vicente del Raspeig (Alicante) \\ macms@ua.es
}

\section{USOS IDEOLÓGICOS DE ELE- MENTOS PRESTADOS DEL EUSKERA EN LA CREACIÓN DE PALABRAS EN ESPAÑOL EN EL LENGUAJE PERIODÍSTICO}

RESUMEN: La neologia es un proceso natural en la evolución diacrónica de las lenguas que, de hecho, encuentra en el lenguaje periodístico un nicho muy fructifero. En este artículo presentamos un análisis del comportamiento morfológico, semántico y pragmático de unos elementos procedentes del euskera documentados en un corpus de prensa elaborado ad hoc. La hipótesis de partida es que se emplean formantes de esta lengua para activar espacios mentales en los receptores que relacionen los neologismos con la violencia terrorista. Este tipo de neologia es especialmente fecunda porque se buscan unos efectos pragmáticos concretos, ya sean como parte del estilo de un periodista o incluso de un medio de comunicación. Se han revisado las hemerotecas digitales de once diarios españoles para estudiar el comportamiento de tres formantes: borroka, batasuno, $-(\mathrm{t})$ arra. La conclusión es que la hipótesis de partida sobre el uso de elementos del euskera para crear neologismos tendenciosos se cumple.

PALABRAS CLAVE: lexicogénesis, préstamos, vasco, espacios mentales, lenguaje periodístico.

SUMARIO: 1 . Introducción, 2. La neologia en el lenguaje periodístico, 2.1. Los neologismos por préstamo en español, 2.2. Neologismos con elementos prestados del euskera, 2.3. El análisis crítico del discurso periodístico, 2.4. Interpretación cognitiva de los neologismos, 2.5 . La ideología de los medios de comunicación, 3. Corpus, 4. Análisis y resultados, 5. Conclusiones.

\author{
IDEOLOGICAL USES OF BASQUE \\ IN THE CREATION OF SPANISH \\ WORDS IN JOURNALISTIC LAN- \\ GUAGE
}

ABSTRACT: Neology is a natural process in the diachronic evolution of language, which founds a very fruitful gap in the language of journalism. This paper presents an analysis of the morphological, semantic and pragmatic behaviour of some linguistic elements coming from the Basque language, which have been documented in an ad hoc corpus from the Spanish press. The initial hypothesis is that formants from this language are used to activate mental spaces that connect neologisms with terrorist violence in the speakers. This type of neology is especially prolific because it seeks concrete pragmatic effects, whether as part of the journalist style or of the media. We have reviewed the digital library of eleven newspapers in order to study the function of three elements: borroka, batasuno and $-(\mathrm{t})$ arra. The conclusion is that the starting hypothesis on the use of elements of Basque to create tendentious neologisms is fulfilled.

KEYWORDS: word creation, borrowings, basque, mental spaces, language of journalism.

SUMMARY: 1. Introduction, 2 Neology in journalistic language, 2.1. The loan neologisms in Spanish, 2.2. Neologisms with elements borrowed from Basque, 2.3. Critical discourse analysis of the press, 2.4. Cognitive interpretation of neologisms, 2.5. Ideology of Spanish media, 3. Corpus, 4. Analysis and results, 5. Conclusions.

\author{
UTILISATIONS IDÉOLOGIQUES \\ DU BASOUE DANS LA CRÉA- \\ TION DE MOTS ESPAGNOLS \\ DANS LA LANGUE JOURNALIS- \\ TIQUE
}

RÉSUMÉ: La néologie est un processus naturel dans l'évolution diachronique du langage, qui trouve une niche très fructueuse dans le langage journalistique. Cet article présente une analyse du comportement morphologique, séman tique et pragmatique de certains éléments linguistiques provenant de la langue basque, qui ont été documentés dans un corpus ad hoc de la presse espagnole. L'hypothèse initiale est que les formants de ce langage sont utilisés pour activer des espaces mentaux qui relient les néologismes à la violence terroriste chez les destinataires. Ce type de néologie est particulièrement prolifique car il recherche des effets pragmatiques concrets, que ce soit dans le cadre du style journaliste ou des médias. Nous avons passé en revue la bibliothèque de onze journaux afin d'étudier la fonction de trois formants: borroka, batasuno et - $(\mathrm{t})$ arra. La conclusion est que l'hypothèse sur l'utilisation d'éléments du basque pour créer des néologismes tendancieux est remplie.

MOTS-CLÉS: création lexicale, emprunts, basque, espaces mentaux, langage du journalisme.

SOMMAIRE: 1. Introduction, 2 Néologie en langage journalistique, 2.1. Les néologismes du prêt en espagnol, 2.2. Néologismes avec des éléments empruntés au basque, 2.3 Analyse critique du discours journalistique, 2.4. Interprétation cognitive des néologismes, 2.5. Idéologie dans les médias espagnols, 3. Corpus, 4 Analyse et résultats, 5. Conclusions. 


\section{Usos ideológicos de elementos prestados del euskera en la creación de palabras en español en el lenguaje periodístico}

María del Carmen Méndez Santos

\section{INTRODUCCIÓN}

Las lenguas son instrumentos de comunicación humana que se comportan como organismos vivos (Adamo y Della Valle, 2006: 5) al adaptarse a las necesidades de sus hablantes. Estas, de hecho, van cambiando a lo largo del tiempo convirtiéndose así en un espejo lingüístico de los acontecimientos históricos (Hernández, 2008). Dado este contexto, es natural entender la neología como un proceso común y habitual. En concreto, esa necesidad puede surgir para conceptualizar nuevas realidades (neología denominativa, Fernández Sevilla, 1982) o para expresar un mensaje con más fuerza o impacto (neologia expresiva, Guilbert, 1975²).

Un representante paradigmático de la creación de nuevas unidades, ya sea con fines estéticos o no, y de la difusión de las mismas, es la prensa (García Platero, 1999; Guerrero Salazar, 2007; Seco, 2007; Gualdo, 2010; entre otros). El estilo periodístico, que no consideraremos un lenguaje técnico, se ha convertido en un referente de habla para la mayor parte de la población (Castillo Carballo et al., 1993: 413) y, por ello, cabe estudiar cómo la creación léxica es empleada en él.

En particular, en este trabajo analizaremos un corpus elaborado ad hoc y de conveniencia con el fin de comprobar qué tratamiento se da a los formantes de origen vasco en la creación léxica en español, principalmente de aquella que aparece recogida y difundida en los medios de comunicación. Este criterio se rige por cuestiones prácticas, porque al ser textos escritos y publicados tienen un carácter más estable, formal y analizable. Por ello, no se analizarán, aunque podría ser otro trabajo, el uso de estos formantes en Twitter o en los discursos orales informales.

Para proceder a este estudio se presenta un marco teórico que justifica el análisis de las creaciones léxicas atestiguadas desde un punto de vista morfológico, semántico, pragmático y de análisis crítico del discurso y seguidamente se ofrecen los resultados constatados. La hipótesis de partida es que se emplean estos elementos de origen vasco para crear neologismos tendenciosos que activen sesgos cognitivos negativos en los receptores de los mensajes al relacionar la información con el espacio mental de la violencia terrorista.

\section{La NEOlogía EN EL LeNGUAJE PERIOdístico}

El lenguaje periodístico es tan diverso como la tipología de sus textos, ya que no se redacta igual una noticia o un reportaje que una

1 Para una revisión crítica de ambos conceptos, léase Estornell Pons (2009) y LlopartSaumell (2016). 
columna de opinión, por ejemplo, o una crónica. En ellos se perciben tendencias como la oralización de las columnas (Mancera Rueda, 2009); la influencia del lenguaje literario o administrativo (García Platero, 2006) o incluso del lenguaje técnico en secciones especializadas (Romero Gualda, 2000). No obstante, observaremos el fenómeno de una forma global, entendiendo que el lenguaje resultante es un producto ecléctico, pero no necesariamente especializado. Quizás, sería más exacto hablar de un continuum de especialización. En todo caso, para el trabajo que nos compete en este artículo se emplearán todos aquellos ejemplos atestiguados, procedan de la sección que procedan. De hecho, en ningún caso las unidades constatadas podrían ser entendidas como neónimos (Cabré, 1993), sino que más bien entran todas dentro de la neología expresiva ${ }^{2}$ propia de las características de libertad estética que se encuentra en editoriales, columnas de opinión, etc.

De hecho, como señalaba Doppagne (1971: 13), "la néologie, pour les communications de masse, est una nécessité". Así, la prensa escrita encuentra en las creaciones léxicas un instrumento de gran fuerza ilocutiva para transmitir una intención comunicativa determinada. Este objetivo puede ser llamar la atención sobre un titular o cuerpo de una noticia y, para ello, en lugar de emplear una palabra común se puede utilizar un préstamo de otra lengua o inventar una creación léxica lúdica por composición culta o sufijación patrimonial (Romero Gualda, 1999; Estornell Pons ,2009; Méndez Santos, $2011^{\text {a }}$; Garcia Platero, 2015; entre otros), por poner algunos ejemplos.

\subsection{Atenuación y cortesía}

En cuanto al uso de préstamos, en un trabajo de corte muy interesante realizado por Gerding Salas et al. (2018), se preguntó a diferentes periodistas chilenos por qué los usaban. Sus principales respuestas fueron que los empleaban porque (1) son conceptos para los que no encuentran equivalentes, (2) porque su uso está extendido, (3) porque llena un vacío semántico de la lengua o (4) porque enriquece estilísticamente el texto. Estas autoras también constataron motivaciones como (5) instrucciones del propio medio de comunicación, o, una respuesta muy sugerente "(6) porque los préstamos construyen realidad". Esto último se sostiene en el hecho de que las lenguas evocan reminiscencias cognitivas y culturales en los lectores (Rodríguez Gutiérrez, 2018) y también despiertan ciertas creencias sociales (un idioma puede ser más elegante que otro, más tecnológico, más útil, etc.), como ocurre, por ejemplo, con especial arraigo en el discurso publicitario (Vega Moreno, 2016). En ese trabajo los periodistas declararon que la lengua de la que más bebian era del inglés; hecho que se perpetúa en el tiempo, teniendo en cuenta que ya en 1996, Emilio Lorenzo dedicó una obra suya a los anglicismos en español. Esta predominancia queda justificada porque en la ór-

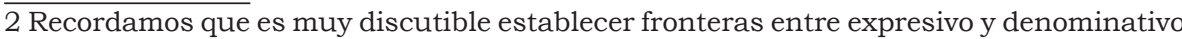
porque la expresividad también es una necesidad denominativa, al fin y al cabo. 
bita occidental este idioma se ha convertido en lingua franca entre otras razones por la globalización, la dominación cultural, los avances tecnológicos y las tendencias socioeconómicas actuales (Marsh, 2018). Diversos estudios demuestran que esta lengua se asocia a lo moderno, lo tecnológico, lo prestigioso (Gerritsen et al., 2007); al igual que existen otras asociaciones tradicionales como la del francés con temas de moda, perfumes o joyas (Lopriore y Furiassi, 2015). Como explicábamos, nuestra hipótesis de partida es que los elementos prestados del euskera se utilizan en el discurso periodístico en muchas ocasiones para que los eductos sean interpretados de manera negativa al relacionarlos con el espacio mental de la violencia terrorista.

Los préstamos no solo se dan en cuanto a la forma o al significado (calcos semánticos), sino que también se pueden prestar elementos morfológicos. Este fenómeno de adición o combinación morfológica tiene un carácter mixto. En otras palabras, en la creación de nuevas unidades se emplea una base patrimonial con un afijo prestado o se combinan palabras acortadas con sufijos u otros elementos también acortados impropios del español. Es especialmente relevante este hecho porque implica la incorporación al sistema del castellano de, por ejemplo, sufijos o sufijoides ajenos, para la creación léxica vernácula. Normalmente estos elementos tienen una productividad moderada y en registros muy determinados, pero no por ello deja de ser un fenómeno muy interesante.

En esta línea se constatan casos de sufijos que ya forman parte del repertorio español como pueda ser el caso de -ing (García Velasco, 2020). Prat Sabater (2019) analiza su recepción lexicográfica y constata que en la mayoría de los casos los lemas incluidos son palabras prestadas, pero como bien señala esta autora no son pocas las unidades creadas con él, aunque sean lúdicas o virguerias puntuales (edredoning o balconing muy reconocidas en el uso). Con los cruces léxicos como mecanismo de formación, Méndez Santos (2011 $1^{\text {b }}$ ) analizaba el caso de -gate en inglés y su incorporación como elemento productivo como equivalente de 'escándalo de x' (Zapaterogate, paellagate). También en esta línea se sitúa el trabajo sobre -exit (Méndez Santos y Álvarez Me1lado, 2021) donde intentan constatar si esta aféresis de Brexit se está incorporando al español: Lexit (León+exit), Catalexit (Cataluña+exit).

No nos centramos en este trabajo en la composición culta, donde también se emplean elementos prestados, pero en este caso de lenguas clásicas como el latín o el griego. No obstante, el comportamiento límite de algunos de los formantes prestados de estas lenguas, como los tomados del inglés, es similar (Méndez Santos, 2011b, 2012).

\subsection{NeOlogismos CON Elementos PRESTAdOS DEL EUSKeRA}

En esta ocasión —dejando de lado la composición culta, los préstamos del inglés o los calcos semánticos - hemos decidido analizar los usos de elementos prestados del euskera que parecen productivos en la creación léxica del español del lenguaje periodístico. Se trata de un aspecto novedoso, ya que no se ha constatado ninguna investigación 
en esta línea.

Existen estudios, eso sí, como los de Fernández de Gobeo Díaz de Durana (2014) sobre la presencia del euskera en el $D L E$, en el que analiza veintidós ediciones para cuantificar la presencia de lexías vascas. No obstante, queremos centrarnos en cómo se emplean ciertas palabras, sufijos o acortamientos de palabras del euskera, no como préstamos, sino como partes empleadas para crear palabras nuevas en español. En especial prestaremos atención a los neologismos ${ }^{3}$ que evocan el terrorismo y la violencia, puesto que son usados para cargar los eductos de valores negativos y para activar un sesgo cognitivo en los receptores. Como explica Veres (2002: 293) en su artículo sobre lenguaje, terrorismo y práctica periodística, las palabras importan y tienen un fuerte poder de sugestión. Defendemos, pues, que al igual que en el estilo literario se emplean palabras específicas para crear la identidad de un personaje, como en el caso de la obra Patria y el uso de ciertos términos vascos (Casas-Olcoz, 2020), ese mismo proceso de creación y activación de determinados espacios mentales también se produce en la creación léxica producida y recogida en el lenguaje periodístico. Estas destacan particularmente por ofrecer una perspectiva negativa, alarmista y sesgada sobre la información. Es posible que estos neologismos estilísticos sean creaciones individuales que no buscan consolidarse, pero el hecho de que se empleen o se difundan en la prensa ya las hace merecedoras de un análisis.

Es más, en este caso, y teniendo en cuenta el contexto sociohistórico español, el hecho de que se empleen elementos prestados del euskera para crear otras nuevas, refleja, en parte, la ideología del medio de comunicación o del periodista que las emplea. Como señala Sala Fernández (2005), técnicamente, los periódicos buscan ofrecer la información de una manera aséptica; pero, si se toma como enfoque de trabajo el análisis crítico del discurso, sabemos que no es posible ignorar el hecho de que, por ejemplo, la selección léxica a la hora de redactar una noticia activa una serie de espacios mentales y provoca una determinada reacción positiva o negativa. De hecho, Guerrero Salazar (2018) hace un análisis, por ejemplo, de los neologismos tendenciosos en los titulares de prensa deportiva en los que se percibe una intención de "criticar, parodiar o ironizar sobre personajes de actualidad".

\subsection{El ANÁLISIS CRÍTICO DEL DISCURSO PERIOdístico}

Este interés que tienen los medios de comunicación por moldear la percepción de la realidad deviene de la necesidad de tener el control sobre la respuesta social y de las actitudes (Van Dijk, 1980a; Fairclough, 2013) que la sociedad - o un grupo dentro de ella tiene- ante cierta información. Esto ocurre -y se irradia- desde la prensa porque es en esta donde se refleja el interés de las élites y partidos políticos por difundir sus discursos. Si seguimos el marco de estudio del Análisis crítico del discurso (Van Dijk, 1997, 1999) entendemos entonces los

3 Este concepto discutible y discutido se empleará en un modo muy general en este trabajo. Para más detalles sobre su definición y delimitación véase Méndez Santos (2011a). 
mensajes mediáticos como un tipo específico de textos. Por todo ello, vemos cómo estos tienen un poder simbólico, persuasivo y conmovedor sobre los lectores (Van Dijk, 1993).

En esta línea, y siguiendo con nuestro objeto de estudio, es posible considerar que en muchas ocasiones los neologismos creados mediante formantes vascos en el lenguaje periodistico buscan provocar ciertos efectos emocionales negativos en el receptor al activar determinados marcos cognitivos (Castells, 2009) relacionados, en este caso, con el imaginario del terrorismo. Así, cuando se emplean estos vocablos se evocan referencias al dolor, la muerte, el miedo, los atentados indiscriminados, al terrorista, a la causa, a la estética o símbolos de los mismos, etc. Por supuesto, estas evocaciones de manera concreta varian en función de cada contexto cultural. No evoca el mismo modus operandi ni estética, ETA que las FARC que AlQaeda.

Entre los diferentes modos de analizar una noticia podemos abordar su análisis textual y su coherencia (Van Dijk, 1980a, 1980b), su superestructura (Van Dijk, 1980a) o la forma del mensaje. De hecho, es posible trabajar con la sintaxis, por ejemplo, si se utiliza la voz pasiva o no para visibilizar u ocultar el agente, el estilo argumentativo y los topoi usados, pero también el léxico. Como explica Van Dijk (2005: 22) no evoca lo mismo terrorista que luchador por la libertad.

En este nivel léxico y morfológico es donde se centra este trabajo que estudia cómo ciertos formantes morfológicos son empleados para la creación de neologismos en español. Además, desde el punto de vista semántico y pragmático también revisaremos cómo la sociedad comprende el mensaje explícito y subyacente en función del contexto sociohistórico y cultural: "Son los usuarios del lenguaje quienes se lo atribuyen o, para ser precisos, son los procesos mentales de los usuarios del lenguaje quienes lo hacen" (Van Dijk, 1997: 37). En este sentido es posible estudiar cómo los discursos crean o sugestionan determinados espacios mentales, en nuestro caso, relacionados con el terrorismo. Sobre esto se profundizará en el siguiente apartado.

\subsection{INTERPRETACIÓN COGNITIVA DE LOS NEOLOGISMOS}

Los criterios de reconocimiento y acotación de los neologismos pasan por cuestiones lexicográficas, la inestabilidad de la forma o su uso extendido, entre otros. Uno de ellos, y muy discutido, como explican Vega Moreno y Llopart Saumell (2017), es el criterio psicológico, es decir, cuando un hablante siente o percibe una palabra o unidad como nueva. Como señalan las autoras, esto es completamente arbitrario porque depende de factores subjetivos.

No obstante, es interesante tener en cuenta cómo cuando aparecen esos neologismos, los hablantes emplean los patrones que ya tienen registrados, sus experiencias previas y conocimiento del mundo (Lavale Ortiz, 2020: 37) para interpretarlos. De hecho, de acuerdo con Cuenca y Hilferty (1999) la interpretación del mensaje depende de nuestro conocimiento social y cultural, que se organiza en modelos cognitivos y culturales. De hecho, la interpretación morfológica social ocurre, ya 
que, como señala Faitelson-Weiser (1993), los hablantes no entienden perfectamente toda palabra nueva, pero si son capaces de captar la significación general al integrarla en un campo morfosemántico e insertarla en el susodicho conocimiento del mundo, histórico y cultural.

Es en este momento donde cobra especial relevancia la teoría de los espacios mentales, ya que la activación provocada por ciertas unidades puede condicionar la interpretación de un neologismo. Así pues, hemos considerado razonable seguir el acercamiento de la Lingüística Cognitiva para este estudio y, sobre todo, tener presente el modelo de la construcción del significado propuesto por Fauconnier $(1985,1997)$ y Fauconnier y Turner (2002) en su teoría de los espacios mentales. De acuerdo con Fauconnier (1997: 11), estos serian pequeñas estructuras conceptuales que son clave para el pensamiento y la comunicación humana.

En nuestro caso, esta teoría de los espacios mentales (Fauconnier, 1997) que defiende la creación de nuevos significados por medio de la combinación de diferentes marcos o dominios, nos servirá para examinar cómo se pueden construir nuevos conceptos en los que se infiere la actitud negativa del hablante ante la realidad que describe a través de la sufijación o la composición con elementos prestados del euskera que se emplean. Es decir, al presentarse diferentes espacios mentales en el neologismo, estos conforman un nuevo significado con el que el emisor pretende generar un determinado efecto perlocutivo en el lector. Nuestra percepción preliminar es que los usos de formantes vascos se emplean para desencadenar una reacción emocional negativa. Es más, el uso de determinadas formas crea, de facto, una suerte de argot propio de un partido político o medio de comunicación que, como indica Rubio Esteban (2018), los identifica como parte de una comunidad de habla con cierta ideologia:

\begin{abstract}
Pues bien, esa lengua reveladora y constituyente o fundante de cada individuo también sirve para revelar el ser en su mismidad de un partido politico. Porque un partido político es ante todo una casa de palabras singulares, propias del colectivo humano que habita esa casa. Las palabras que usan los partidos políticos no sólo sirven para transmitir y revelar - ¡y también para ocultar, claro! -su ideología e intenciones politicas subyacentes a la misma, sino que también "su" vocabulario delimita el espacio politico que cada partido ocupa.
\end{abstract}

En otras palabras, compartir y usar ciertos vocablos crea identidad de grupo y se convierte en parte del ritual y de las prácticas de una comunidad (Ruiz Gurillo, 2019).

\title{
2.5. LA IDEOLOGÍA DE LOS MEdios de COMUNiCACión
}

Los textos presentes en la prensa varian en su formato, estilo y objetivos esperables. Así, no se dispone la información del mismo modo ni esta se interpreta igual cuando se trata de una noticia, que cuando es una columna de opinión, es decir, es esperable encontrarse diferentes tipos de recursos estilísticos, por ejemplo. El respeto a los géneros ayuda al lector a ubicarse y leer. Entre los textos más frecuentes en la prensa general podríamos desta- 
car las columnas de opinión y las noticias que, como explica Gomis (2008), se espera que sean objetivas, neutras y sin manipulaciones.

No obstante, como explica el Análisis critico del discurso, estos mensajes pueden ser empleados por las élites para perpetuar su estatus o promover ciertas ideas. El estudio de la relación entre ideología, poder y acceso a la información es muy fructífero en el contexto periodístico. De hecho, a pesar de que, a priori, se pudiera esperar que los medios fueran independientes y apolíticos, es posible señalar que esto no es así. De hecho, en el contexto español actual, los medios digitales todavía se han convertido en un mecanismo aún más potente de ciertos aparatos sociales, ideológicos y políticos para transmitir un mensaje sesgado, neoliberal, descarnado, parcial (López de la Cerda y del Valle, 2007).

En este punto cabe señalar de la prensa española que es reconocida técnica y popularmente por sus inclinaciones ideológicas. Por ejemplo, en el trabajo de Igartua, Muñiz y Cheng (2005) se concluye que $E l$ País presenta una visión más progresista que el $A B C$ en cuanto a la inmigración que se muestra más conservador. Teruel Rodríguez (2013) en su análisis de los editoriales estudia, además de los anteriores, el framing y la agenda setting de El Mundo. En su análisis incluso percibe cómo cada periódico critica más o menos al partido político con el que es afin. En el caso de este diario se señala que reprocha menos al PP que El Pais y ambos son superados en afinidad con este por el $A B C$. Entre los diarios analizados en este trabajo suelen calificarse como conservadores $\mathrm{La} \mathrm{Voz}$ de Galicia, Libertad digital, Ok Diario. No obstante, no es posible encontrar quórum ni detalles sobre todos los periódicos analizados y no todos ellos tienen una tendencia tan marcada y percibida como indiscutible. Además, prensa considerada de izquierdas puede recoger estos vocablos para reflexionar sobre los mismos, citando declaraciones, etc. En todo caso, en general, es posible afirmar que la población española percibe la prensa con inclinaciones ideológicas que los llevan incluso a desconfiar de los datos presentados. De hecho, en el informe de Reuters sobre los medios digitales de 2021 se dice que solo un $36 \%$ se cree las noticias publicadas y destaca particularmente de España que los datos encajan "particularly well with research on the hostile media' phenomenon, a long tradition of research showing that opposing political partisans both have a tendency to see media coverage as biased against them". Estos sesgos se materializan a través de, entre otros mecanismos, en el léxico y las creaciones neológicas empleados.

A continuación, presentamos el análisis de los vocablos presentes en este trabajo de manera pormenorizada atendiendo a sus aspectos morfológicos y semánticos, en primer lugar, y a las connotaciones pragmáticas y discursivas que evocan, posteriormente.

\section{Corpus}

Para realizar este estudio sobre el uso de formantes vascos en español se ha creado un corpus de conveniencia limitado en el tiempo y cuyas fuentes son de origen periodístico. Decimos que es de 
conveniencia porque para comenzar la búsqueda se seleccionaron diarios donde se encontró algún registro antes de iniciar el análisis sistemático de todos, esto es, no hemos escogido revisar, por ejemplo, los diarios más vendidos, sino aquellos donde habíamos encontrado los ejemplos que desencadenaron la idea de este trabajo.

En total se han examinado las hemerotecas digitales de once periódicos ${ }^{4}$ diferentes buscando por palabra exacta y con códigos de búsqueda avanzada. La representatividad puede ser discutida, pero, en primer lugar, cabe destacar que no vamos a analizar la productividad de los elementos de manera estadística, sino la conceptualización que encierran y, en segundo lugar, se ha buscado en diarios de diferentes regiones españolas para poder abarcar de la mejor manera posible la extensión geográfica y la difusión que ello implicaría. Claro está, y es de esperar, que algunas palabras solo aparecen en un periódico porque, como ya se ha explicado, el emplear un vocabulario dado se crea una sensación de filiación a un grupo, a una ideología o a un partido, hecho por el que, una palabra puede ser esperable en un periódico, pero no en otro. En este caso se encuentra la palabra, por ejemplo, moro borroka o butifarra borroka, ambas solo atestiguadas en el diario conservador Alerta digital. Es más, incluso algunas de las creaciones pueden formar parte del estilo personal de un periodista y no de un medio de comunicación en general. Podríamos citar en este caso la creación foto borroka que solo hemos documentado en $A B C$ edición Galicia y empleado por José Luis Jiménez.

Los elementos del euskera recogidos en este corpus son borroka (tabla 1), batasuno (tabla 2) y -(t) arra (tabla 3). Como explicamos, se produjo primero una constatación informal de su utilización para crear reacciones negativas en los lectores y después se hizo una primera búsqueda informal. Esta constatación es subjetiva de la investigadora por lo que puede haber más formantes que aparezcan esporádicamente empleados. No obstante, después del análisis elaborado podemos afirmar que estos elementos del euskera son los más frecuentemente empleados para crear neologismos en la prensa. Una vez delimitadas las formas vascas que están siendo utilizadas para crear nuevas palabras con esos fines pragmáticos, ya se produjo la búsqueda sistemática y exhaustiva.

4 En concreto: $A B C$, Alerta digital, Ok Diario, Voz Populi, Crónica Global, Valencia Plaza, La Voz de Galicia, La última hora, El nacional.cat, Las provincias, El Periódico de Aragón. 


\begin{tabular}{|c|c|c|c|c|}
\hline $\begin{array}{l}\text { Ele- } \\
\text { mento }\end{array}$ & $\begin{array}{l}\text { Procedi- } \\
\text { miento }\end{array}$ & Type & Tokens & Ejemplos \\
\hline \multirow{7}{*}{ Borroka } & \multirow{7}{*}{$\begin{array}{l}\text { Elemento } \\
\text { composi- } \\
\text { tivo (por } \\
\text { trunca- } \\
\text { miento } \\
\text { de kale } \\
\text { borroka) }\end{array}$} & $\begin{array}{l}\text { Turismo } \\
\text { borroka }\end{array}$ & $7^{5}$ & $\begin{array}{l}\text { - De la turismofobia a la "turismo borroka", ante el silencio } \\
\text { de Colau (Estrella Digital, 2-8-2017). } \\
\text { - Se deberia actuar legalmente contra el turismo "borroka" } \\
\text { promoviendo una investigación policial en profundidad (...) } \\
\text { (ABC.es, 3-8-2017). } \\
\text { - Turismo borroka separatista, pero, ¿qué hay de lo mio? } \\
\text { (Vozpopuli, 8-8-2017). }\end{array}$ \\
\hline & & $\begin{array}{c}\text { Moro } \\
\text { borroka }\end{array}$ & (hápax) & $\begin{array}{c}\text { - La 'moro borroka' se impone en el País Vasco: Una reyerta } \\
\text { navajera entre magrebies se salda con un herido grave en } \\
\text { Bilbao (Alerta digital, 20-1-2012) }\end{array}$ \\
\hline & & $\begin{array}{l}\text { Butifarra } \\
\text { borroka }\end{array}$ & $3^{6}$ & $\begin{array}{c}\text { - La "butifarra borroka" se extiende a Baleares: Indepen- } \\
\text { dentistas de Arran atacan un restaurante y varios yates en } \\
\text { Palma (Alerta Digital, 2-8-2017). } \\
\text { - ¿Butifarra borroka o caso fortuito? Incendiados una vein- } \\
\text { tena de vehículos en un barrio de Hospitalet (Alerta digital, } \\
19.9 .2017)\end{array}$ \\
\hline & & $\begin{array}{l}\text { Foto } \\
\text { borroka }\end{array}$ & 2 & $\begin{array}{l}\text { - La "foto borroka" del último alcalde fichado por el PP en } \\
\text { Orense }(A B C, 27-8-2020) .\end{array}$ \\
\hline & & $\begin{array}{l}\text { Polo } \\
\text { borroka }\end{array}$ & (hápax) & $\begin{array}{l}\text { - El futuro de Nissan, escuelas cerradas y polo borroka (Cró- } \\
\text { nica Global, 16-5-2020). }\end{array}$ \\
\hline & & $\begin{array}{c}\text { Caye } \\
\text { borroka } \\
\text { Caye-bo- } \\
\text { rroka }\end{array}$ & $7^{7}$ & $\begin{array}{l}\text { - La segunda fase consistiria en aprovechar el malestar de } \\
\text { amplios sectores de la ciudadania (...) y que habría tenido } \\
\text { como epicentro el elitista Distrito madrileño de Salamanca } \\
\text { (Cayeborroka) (Alerta Digital, 15-5-2020). } \\
\text { - Paella de Guardia: Caye Borroka y pagafantismo parlamen- } \\
\text { tario (Valencia Plaza, 21-5-2020). } \\
\text { - Hay múltiples denominaciones alternativas, todas con } \\
\text { mucha miga, como "kale pochola" o "Caye borroka" (Valencia } \\
\text { Plaza, 16-5-2020). } \\
\text { - } 6 \text { cosas que no sabias de la calle Núnez de Balboa, la "gran } \\
\text { alameda" de los 'CayeBorroka' (La última hora.es, 16-5- } \\
\text { 2020). } \\
\text {-El pasapalabra del coronavirus: de la "Cayeborroka" a la } \\
\text { "superioridad moral" (La Voz de Galicia, 15-5-2020). }\end{array}$ \\
\hline & & $\begin{array}{c}\text { Cata } \\
\text { Borroka }\end{array}$ & (hápax) & $\begin{array}{c}\text { - Cata borroka. Lo dijo repetidamente Mariano Rajoy cuando } \\
\text { le planteaban hacer un referéndum como salida "dialoga- } \\
\text { da" al conflicto político catalán: "Ni quiero ni puedo"(...) (El } \\
\text { nacional.cat, 10-4-2018). }\end{array}$ \\
\hline
\end{tabular}

Tabla 1: Ejemplos registrados para el truncamiento borroka

5 Como dato general adicional se apuntan los 434 resultados atestiguados en Google. 6 Los tres solo se documentan en este diario.

7 Como dato general adicional se apuntan los 16100 resultados atestiguados en Google. 


\begin{tabular}{|c|c|c|}
\hline $\begin{array}{l}\text { Elemen- } \\
\text { to }\end{array}$ & $\begin{array}{l}\text { Procedi- } \\
\text { miento }^{1}\end{array}$ & Ejemplos \\
\hline \multirow[b]{2}{*}{$\begin{array}{l}\text { Bata- } \\
\text { suno }\end{array}$} & $\begin{array}{l}\text { Sustanti- } \\
\text { vo (trun- } \\
\text { camiento, } \\
\text { préstamo } \\
\text { y rese- } \\
\text { mantiza- } \\
\text { ción) }\end{array}$ & $\begin{array}{c}\text { - Este hecho ha dado lugar a situaciones como la que se vivió el miércoles en el } \\
\text { Ayuntamiento de Durango (Vizcaya), donde los batasunos se desvincularon de nuevo } \\
\text { de un texto de rechazo hacia estos actos violentos (ABC, 28-5-2020). } \\
\text { - Los 'batasunos' catalanes también espían: La CUP contrató a Método } 3 \text { para investi- } \\
\text { gar al padre del alcalde de Valls (CiU) (Alerta Digital, 24-2-2013). } \\
\text { - Me ha llamado la atención el generalizado lesbianismo de las batasunas (Alerta } \\
\text { digital, 8-9-2012) }\end{array}$ \\
\hline & $\begin{array}{l}\text { Adjetivo } \\
\text { (trunca- } \\
\text { miento, } \\
\text { préstamo } \\
\text { y conver- } \\
\text { sión) }\end{array}$ & $\begin{array}{l}\text { - El PP del Senado se aproxima al lenguaje batasuno en una moción para ganarse el } \\
\text { apoyo del PNV (Ok Diario, 13-4-2018). } \\
\text { - La iniciativa parte de Ernai, las juventudes batasunas, que han colocado varias de } \\
\text { estas pancartas en pleno centro de Bilbao (Alerta digital, 23-12-2019). } \\
\text { - El peinado batasuno. El hábito no hace al monje, pero en este caso es que todos los } \\
\text { monjes se ponen el mismo hábito (Las Provincias.es, 22-10-2016). } \\
\text { - La lista amparada por el TC se estrena pidiendo el voto batasuno y sin condenar la } \\
\text { violencia (ABC, 23-5-2009). } \\
\text { - Porque el PP del Senado se aproxima al lenguaje batasuno en una moción para } \\
\text { ganarse el apoyo del PNV (ABC, 14-4-2018). } \\
\text {-Uno de los separatistas arrebató a Macià su teléfono móvil y otra chica, con aspecto } \\
\text { batasuno, golpeó a su compañero con un palo (Ok Diario, 30-08-2018). }\end{array}$ \\
\hline
\end{tabular}

Tabla 2: Ejemplos de uso de batasuno

\begin{tabular}{|c|c|c|c|c|}
\hline Elemento & Procedimiento & Type & Tokens & Ejemplos \\
\hline -tarra (etarra) & $\begin{array}{l}\text { Cruce léxico (trun- } \\
\text { camiento) }\end{array}$ & Bildutarra & 276 & $\begin{array}{c}\text { - Un diputado } \\
\text { bildutarra 'limpia' } \\
\text { su curriculum } \\
\text { oficial y se queda } \\
\text { sin máster en } \\
\text { derechos huma- } \\
\text { nos (Ok Diario, } \\
\text { 16-4-2018) } \\
\\
\text { - Los bildutarras } \\
\text { fracasan en su } \\
\text { iniciativa para in- } \\
\text { sultar a la Guar- } \\
\text { dia Civil (ABC, } \\
\text { 1-9-2014). } \\
\\
\text { - Todo ha empe- } \\
\text { zado cuando } \\
\text { Uriarte ha cali- } \\
\text { ficado a Iñarritu } \\
\text { de "bildutarra", } \\
\text { para denunciar } \\
\text { que el presidente } \\
\text { español, Pedro } \\
\text { Sánchez, tiene su } \\
\text { apoyo (El Nacio- } \\
\text { nal.cat, 10-6- } \\
\text { 2020). } \\
\\
\text {-Ayer se retrató en } \\
\text { el despacho con } \\
\text { Gabriel Rufián y } \\
\text { Mertxe Aizpurua, la } \\
\text { portavoz bildutarra } \\
\text { (Crónica Global, } \\
\text { 17-9-2020). }\end{array}$ \\
\hline
\end{tabular}

Tabla 3: Types y tokens construidos con -(t)arra

8 Su número de apariciones es altísimo (cientos) en estos diarios y ya está registrada en el $D L E$ como adjetivo. Nos centraremos pues en los aspectos semánticos atestiguados y no tanto en justificar su existencia mediante el conteo de tokens. 


\section{Análisis y Resultados}

A continuación, se ofrece un análisis de cada elemento prestado del euskera recogido en este corpus de palabras en español del lenguaje periodístico con intenciones de activar un espacio mental negativo relacionado con el terrorismo.

\subsection{BORROKA}

Borroka es una palabra usada en español como adjetivo principalmente, pero cuyo origen es un sustantivo que significa lucha, pelea, combate o confrontamiento ${ }^{5}$. Este hecho se debe a que el préstamo al español no ha sido directo de sustantivo a sustantivo, sino que el origen de esta incorporación se sitúa en un truncamiento producido sobre la expresión kale borroka. Esta unidad léxica compleja consta con 52 apariciones en el Corpus de Referencia del Español Actual (CREA) de la Real Academia Española, siendo la más antigua de 1999:

Dirigentes del PNV y EA consideran que, más allá de las condenas, lo decisivo es que desaparezca la kale borroka y que la izquierda abertzale deje de proporcionar una cobertura política a la violencia, lo que supondría un salto cualitativo histórico (El Diario Vasco, 04/05/1999).

La kale borroka es una forma de designar la violencia callejera en Euskadi relacionada con la izquierda nacionalista e independentista. Esta palabra no aparece recogida en el Diccionario de la Lengua Española (DLE), pero sí en el Diccionario de Uso del Español (DUE, 2007: 17236). En este se define como "En el País Vasco, disturbios callejeros promovidos por la izquierda abertzale como medio de lucha politica". El Diccionario Clave ${ }^{7}$ (2003: 1166) explica en cuanto a su empleo que "su uso es innecesario y puede sustituirse por violencia callejera". Alvar Ezquerra (2003: 642) apunta un matiz importante para el uso que luego se ha dado a este truncamiento: "Violencia callejera de carácter terrorista en el País Vasco".

Como se puede deducir, aunque no esté en el $D L E$ ni en el $D E A$ (Diccionario del español actual, 1999) es un término este, kale borroka, muy difundido en el uso periodístico. Por poner un ejemplo, solo en la hemeroteca del $A B C$, su búsqueda arroja 2441 resultados. Sobre las implicaciones políticas de su utilización o no, no nos compete discutirlo aquí, pero sí que hay trabajos desde el punto de vista sociológico que analizan los efectos del uso de este término (Rekalde, 2003). Justamente en una nota de la Guardia Civil $(2003)^{8}$ se consideraba que este "terrorismo de baja intensidad" tuvo un gran auge durante los años 90.

Cabe pensar pues que han pasado los años suficientes para que en el imaginario colectivo la idea de la kale borroka haya cuajado relacionándola con un tipo concreto de terrorismo informal o menos

9 Definición de borroka: https://hiztegiak.elhuyar.eus/eu_es/borroka.

10 En la edición de 2002 no aparecía todavía.

11 Diccionario Clave: Diccionario de uso del español actual (2003), Madrid: SM.

8 https://cutt.ly/Kgc8d6t. 
organizado, callejero. Es posible asi justificar que se produjese el truncamiento de modo que se comenzó a usar borroka, no como lucha (sentido originario), sino como un nuevo elemento compositivo resemantizado como "acto de violencia de carácter terrorista informal" o conjunto de personas que la ejercen contra algo. Al amparo de ese sentido es posible entender la aparición de neologismos posteriores como turismo borroka, moro borroka, butifarra borroka, etc. (véase tabla 1). De hecho, la Fundeu recoge una nota sobre el uso de turismo borroka:

Además, en los medios se observa cierto uso de la voz vasca borroka, que
significa 'lucha', en relación con este asunto, como en "Turismo-borroka":
los abertzales se unen al boicot de los radicales de la cUP". Lo recomenda-
do en este caso es optar por "turismo borroka", esto es, escrito en dos pala-
bras, con turismo en redonda y borroka en letra cursiva por ser un término
vasco. También es válido "turismo-borroka", con guion y borroka en cursiva.
(https://www.fundeu.es/recomendacion/turismofobia-neologismo-valido/).

Como se puede observar del corpus, la tendencia es a presentarlo con un espacio separando las dos palabras. Ambas palabras conservan su unidad acentual y borroka suena como [borróka].

Estas creaciones no son inocentes y pretenden bien despertar temor por las connotaciones de inseguridad, peligro, etc. que evoca la palabra borroka (moro borroka, turismo borroka), bien incluso, crear ciertos tintes lúdicos o expresivos desde el punto de vista pragmático como en polo borroka o Cayeborroka. La denostación y desprecio se trasluce en creaciones como butifarra borroka. En este caso se pretende crear una expresión analógica de la kale borroka, pero que se identifique con la realidad catalana y del proceso de independencia, en este caso, casi burlesca. No obstante, esta creación no parece haber triunfado y solo se emplea en un medio, Alerta digital, de corte conservador. De este uso es posible inferir la postura ideológica del diario ante temas como la independencia de Cataluña.

En el caso de palabras creadas con borroka, el elemento patrimonial puede hacer referencia al objetivo de la violencia (turismo borroka) o al agente de la acción (Cayeborroka, moro borroka) ya sea con un agente concreto o por metonimia: polo borroka. Incluso se pueden emplear elementos que relacionan la violencia con un ámbito geográfico específico: Cataborroka, butifarra borroka. En el segundo caso se emplea una base que busca aludir a Cataluña, pero con efectos humorísticos. En el caso de foto borroka se refiere a una foto de un alcalde apoyando unas posiciones interpretadas como probanda terrorista $\mathrm{y}$, en este caso, borroka se emplea casi como un adjetivo relacional.

La expresividad, como anunciamos en el marco teórico, es fundamental a la hora de justificar estos usos en la prensa y también la idea de crear una comunidad de habla porque, por ejemplo, algunas como butifarra borroka, foto borroka o moro borroka, solo aparecen en un medio. Es decir, se busca exacerbar las respuestas y la complicidad con el lector de un medio de comunicación con una línea editorial ideológica muy marcada que se configura también a través de sus usos lingüísticos. Así, lo percibía Iosu del Moral, secre- 
tario general de Podemos en Donostia en $2017^{9}$, en un artículo en el que decía que estas creaciones buscan una interpretación pragmática clarísima: despertar el miedo o como mínimo, las suspicacias:

\begin{abstract}
Una vez más la derecha (...) distorsiona un mensaje desde la misma raíz a fin de mantener sus propios intereses. A la iniciativa (...) de apostar por otro modelo turístico, la derecha cae en la simpleza de que algunos están en contra del turismo (...) Así que, sin ningún tipo de moderación ni mesura, su ejército de ridículos tertulianos y hooligans arranca un bombardeo masivo por los diferentes platós de televisión, lanzando una batería de falacias que comienzan con la memez (...) de que estos están en contra del turismo, para inmediatamente introducir con toda la intención una serie de términos del tipo turismofobia o turismo borroka que les permita a sus miembros más fanáticos alcanzar el climax con aquello tan retorcido que alude a que todo es ETA. (Iosu del Moral, 2017).
\end{abstract}

Por otra parte, se sitúan los elementos como polo borroka (hápax) o cayeborroka que apuntan más a creaciones expresivas, sí, pero con tintes lúdicos. En ambos casos se hace referencia a las manifestaciones que se produjeron en barrios adinerados de Madrid durante el confinamiento por la pandemia del COVID-19 en el año 2020. Así, los periodistas recogiendo el testigo de los usos creativos en Twitter comienzan a usar este término para hablar de los disturbios callejeros provocados por los "cayetanos" y "borjamaris":

La \#CayeBorroka de los cayetanos y borjamaris: Twitter estalla contra la manifestación en el barrio de Salamanca (Laúltimahora.es, 14-5-2020).

En este caso se emplea como base la forma apocopada del antropónimo Cayetano. Esta palabra, Cayeborroka, fue usada en la etiqueta por primera vez en Twitter por el usuario Javier Durán (@tortondo).

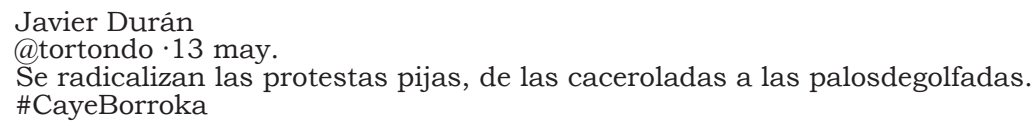

El nombre Cayetano, así como Borjamari ${ }^{10}$, es identificado como propio de gente pija, con alto poder adquisitivo, una ideología conservadora y una forma de vestir particular. El uso de Borjamari es más antiguo que el de Cayetano y está más extendido en el uso, aunque actualmente, quizás por la influencia de canciones como la de Carolina Durante llamada precisamente Cayetano $^{11}$, en el imaginario colectivo popular los pijos en 2020 se llaman así12:

\footnotetext{
Borjamari: dícese en Madrid del pijerío de derechas, pantalón de pinzas, camisa de marca, preferentemente a rayas, un toque de gomina y el jersey colgado del cuello los domingos al mediodia en la sierra o en las terrazas invernales del barrio de Salamanca (La Vanguardia, 3-1-2012).
}

\footnotetext{
9 https://cutt.ly/Ogc8fP1.

10 https://www.lavanguardia.com/politica/20120103/54243579139/borjamaris-enfadados.html. 11 https://www.youtube.com/watch?v=ZiUhV12G024

12 https://www.revistavanityfair.es/poder/articulos/carolina-durante-cayetano-cancion/29996: Por qué todos los pijos se llaman Cayetano.
} 
El ejemplo recogido en Crónica Global emplea otro elemento característico de los pijos para hacer la metonimia parte-todo: el polo (de Lacoste), pero no ha tenido tanto éxito ni repercusión como Cayeborroka.

Elfuturo de Nissan, escuelas cerradas y polo borroka (Crónica Global, 16-5-2020).

Otra prueba del grado de penetración de borroka en español es que no solamente se emplea como elemento compositivo, sino que también se comporta como adjetivo incluso como sustantivo autónomo. En ejemplos como los siguientes, se aprecia cómo el concepto borroka se ha convertido también en caracterizador de las personas que la practican con un estilo de vestimenta y corte de pelo particulares.

Expliquese. F.G. Es que, entre vascos, fuera de Euskadi, nos reconocemos fácil; aunque hay tipos más reconocibles, como los adeptos al estilo borroka ( $L a$ Voz de Galicia.es, 13-11-2016, Suplemento semanal).

Últimamente, el transformismo de Anna Gabriel, que ha pasado de pija-borroka a pija-pija en lo que se tarda en avión (La Voz de Galicia, 23-3-2018).

Es más, incluso se emplea borroka como sustantivo, pero no como lucha, sino como sujeto agente que realiza un acto de violencia callejera. La palabra vasca formada para ello es borrokalari. No obstante, como se observa en el siguiente ejemplo, primero se produjo el préstamo, luego el truncamiento y resemantización, para por último pasar por un proceso de conversión morfológica, porque no se emplea, de hecho, borrokalari para referirse al agente que sería la expresión original.

Los 'borroka' de la CUP se erigen en el ariete de la campaña del referéndum (Voz Populi, 2-8-2017).

Yo iba con el paraguas, tapada hasta por aquí, con el chal puesto, y en el bar, uno que hay cerca de casa que es todo de borrokas, pues yo pasé, y salieron por una puerta... (ABC, 6-6-2016).

En suma, a raíz de esta serie de palabras creadas por composición con el elemento borroka a través de un truncamiento como mecanismo morfológico y una resemantización, es posible afirmar que en el imaginario popular se procesan estas creaciones evocando la idea de "actos de violencia callejera informal de carácter terrorista". Cualquier creación parte de ese valor central y después, dado el contexto pragmático y con qué elementos se combine, pueden darse valores lúdicos, burlescos, etc. Es más, incluso se han constatado casos en los que borroka ha sufrido un proceso de conversión y se comporta como un adjetivo o un sustantivo con nuevos valores que se asocian al estilo propio de las personas que practican la kale borroka.

\subsection{Batasuno}

Si en el caso de borroka podía surgir la duda de si el origen era el sustantivo prestado directamente sin más, hecho que ya se ha explicado que no es así por todos los valores semánticos que encierran en español las palabras compuestas 
con él, no es este el caso de batasuno que por sí solo no significa nada en euskera. De hecho, batasuna significa unidad sin más.

Como recoge el DLE (2019), batasuno es un adjetivo que se emplea para referirse a lo "Perteneciente o relativo a la coalición política vasca Herri Batasuna" o "Afiliado a la coalición politica vasca de Herri Batasuna. Parlamentario batasuno. U. t. c. s.".

En este caso también se produjo un truncamiento del nombre oficial del partido Herri Batasuna. Esta coalición política nacida en el año 1978 fue considerada afin a la causa de la banda terrorista ETA. Este partido derivó en Batasuna y este fue ilegalizado en 2003. Así pues, en los usos y creaciones posteriores a su desaparición se emplea el nombre batasuno de una forma genérica, es decir, hay una extensión del significado, porque no se refiere solo a los miembros del partido Herri Batasuna, sino en general a los afiliados o representantes de partidos considerados nacionalistas vascos e independentistas. De hecho, como se ve en los siguientes casos, el uso del $A B C$ en 2020 se refiere a una persona perteneciente al partido político Bildu. Etiquetarle del mismo modo denota una intención de relacionar ambos partidos y connotaciones negativas de apoyo al terrorismo, etc.

Este hecho ha dado lugar a situaciones como la que se vivió el miércoles en el Ayuntamiento de Durango (Vizcaya), donde los batasunos se desvincularon de nuevo de un texto de rechazo hacia estos actos violentos (ABC, 28-5-2020).

Es más, todos esos valores relacionados con la estética, la ideología o la forma de vivir nacionalista o independentista se encierran en esa palabra para dar lugar a combinaciones como las siguientes donde batasuno se comporta sintácticamente como adjetivo y no se refiere a perteneciente o relativo a Herri batasuna. En lo que se refiere al aspecto físico hay una fuerte vinculación en el imaginario colectivo con el tipo de peinado que suelen llevar estas personas y de su forma de vestir con la ideologia politica que defienden. Así se habla de peinado batasuno (en algunos diarios incluso de peinado borroka) para referirse a un corte de pelo con flequi1lo, laterales rapados con una forma muy definida e identificable ${ }^{13}$.

El peinado batasuno. El hábito no hace al monje, pero en este caso es que todos los monjes se ponen el mismo hábito (Las Provincias.es, 22-10-2016).

Uno de los separatistas arrebató a Macià su teléfono móvil y otra chica, con aspecto batasuno, golpeó a su compañero con un palo (Ok Diario, 30-80-2018).

Esta palabra está tan arraigada que ha dado lugar a derivados como batasunizar o batasunización. Incluso hay una serie de colocaciones muy frecuentes al más puro estilo batasuno o lenguaje batasuno, muy repetidas en los medios de comunicación.

España se batasuniza (ABC, 18-6-2015).

13 Esta columna de opinión muy hostil a este tipo de estética dice lo siguiente: "Cuando ves semejante adefesio capilar sabes que estás frente a un simpatizante de la izquierda abertzale (...)" (Público, 9-2-2014). 
La batasunización de la actual líder de la CUP es evidente desde su peinado hasta su forma de vestir, aunque politicamente se ha atrevido a mucho más que Batasuna (Alerta digital, 17-9-2017)

El PP del Senado se aproxima al lenguaje batasuno en una moción para ganarse el apoyo del PNV (OK Diario, 13-4-2018).

En suma, el formante batasuno, truncamiento de Herri Batasuna, pasó al español para referirse a los miembros o a los hechos relativos con ese partido que se consideraba probanda terrorista ETA. No obstante, a pesar de desaparecer como partido, su relación de cercanía al terrorismo quedó en el imaginario periodístico y popular para referirse a partidos independentistas y personas afines. Tanto es así, que se produjo un salto semántico y surgieron derivados como batasunizar y como adjetivo podría interpretarse como calificativo: peinado batasuno. Discutir ahora si este adjetivo todavía es solamente relacional, no es el foco del trabajo, pero queda apuntado para futuros análisis. En este último caso se refiere más a una serie de atributos vinculados a una estética y moda.

\section{3. - $(\mathrm{t})$ ARRA}

El sufijo relacional -arra (Rainer, 1999) sirve para crear adjetivos epicenos y sustantivos a partir de radicales nominales y viene de la terminación vasca de función análoga (Pharies, 2002).

La palabra más difundida en español es etarra. Esta está recogida en el $D L E$ y es definida como " 1 . adj. Perteneciente o relativo a la organización terrorista ETA. / 2. adj. Integrante de ETA. U. t. c. s.”.

En principio el sufijo euskera -arra solo tiene un valor relacional para la creación principalmente de gentilicios, aunque la forma etarra no siguió ese patrón general. No obstante, en el caso de la creación que atestiguamos no se emplea solo el sufijo, sino lo que podría ser el truncamiento de tarra. Probablemente sea más cabal pensar esto por las connotaciones semánticas del educto bildutarra. En este caso sería un cruce léxico de Bildu con etarra:

Un diputado bildutarra 'limpia' su currículum oficial y se queda sin máster en derechos humanos (OK Diario, 16-4-2018).

Así se podría entender la razón por la que se creó una palabra para relacionar y dejar patente la relación entre el nuevo partido político Bildu y ETA, dado que no son coetáneos, pero ciertos movimientos políticos y sociales consideran que son los herederos de posiciones independentistas de la lucha armada representada políticamente. Está claro que esta creación no es inocente ni neutra.

Curiosamente solo atestiguamos esta formación creada mediante cruce léxico con etarra, pero está ampliamente documentada en diferentes periódicos y goza de bastante cantidad de recurrencias. El resultado es una palabra empleada tanto como adjetivo como sustantivo. En ambos casos se muestra como epiceno y concuerda en número cuando se presenta en plural. 


\section{Conclusiones}

La neología es un proceso natural que ocurre en las lenguas de forma espontánea o planificada. Su necesidad puede venir dada de necesidades denominativas o expresivas y es empleada en todos los registros, ámbitos y contextos. Esta es foco de estudio cuando se analiza el lenguaje periodístico pues se considera que la gran difusión de este provoca que el modelo de lengua empleado en él se convierta en modelo lingüístico para gran parte de la población.

Estos neologismos en el discurso periodístico pueden originarse por diferentes razones denominativas, estilísticas o expresivas, pero lo que está claro es que el hecho de que un periodista o un medio emplee ciertas palabras exclusivas de su medio le ayuda a configurar su identidad ideológica. Este es el caso de algunas de las creaciones atestiguadas en este trabajo de manera que se conforma una especie de argot que sirve para crear una comunidad de habla de una ideología determinada.

En el caso del español, los elementos prestados procedentes del euskera atestiguados en el corpus ad hoc elaborado para este trabajo son empleados claramente para crear unidades léxicas que activan espacios mentales negativos asociados al terrorismo para provocar una reacción emocional negativa y adversa en los lectores como se ha demostrado.

En particular se ha atestiguado este uso perlocutivo en el caso de borroka, batasuno y -(t)arra. En los tres se pretende evocar la violencia terrorista de la desaparecida ETA, el miedo, el caos, la violencia, etc. En el caso de borroka -truncamiento de kale borroka- este ha sufrido una resemantización. Así, en español es posible afirmar que este elemento se procesa evocando la idea de "actos de violencia callejera informal de carácter terrorista". Este valor justificaría la aparición de nuevas formas como Cayeborroka. Es más incluso se emplea este formante convertido en adjetivo y sustantivo para designar a las personas que la practican o para calificar su estilo de ropa. Por su parte, el elemento batasuno, proveniente del truncamiento de Herri Batasuna, se usa en español para referirse a los miembros o a los hechos relativos con ese partido o de cualquier otro que se considere pro banda terrorista ETA o independencia de corte radical. Tanto es así que aparecen derivados como batasunizar y como adjetivo se comporta no solo como relacional, sino también, podríamos defender, como calificativo: peinado batasuno, lenguaje batasuno. En estos casos se hace referencia a una serie de atributos vinculados a una moda y a un tipo de comportamiento. Por último, se atestigua un educto creado mediante un posible cruce léxico: bildutarra. En este caso se crea una palabra intencionadamente para relacionar un partido actual con la banda terrorista ETA que no es contemporánea de dicha agrupación política, pero mediante este educto se busca establecer un vínculo y evocarlo en los receptores del discurso.

Las creaciones morfológicas atestiguadas emplean préstamos de otra lengua, el euskera, pero los hablantes pueden interpretarlas utilizando el conocimiento del mundo que poseen. Estos espacios mentales evocan intencionalmente el terrorismo y el miedo. Desde un punto de 
vista pragmático es imposible obviar los efectos perlocutivos buscados con estos eductos, dado que se intentan crear una respuesta reaccionaria y muy beligerante. Curiosamente muchos de ellos solamente son empleados en periódicos de cierta tendencia ideológica lo que nos lleva a afirmar que esta estrategia de empleo de cierto vocabulario ayuda a configurar la comunidad de habla afin a sus postulados y se convierte en una especie de argot y muestra de pertenencia al grupo. Para el futuro queda pendiente realizar un estudio empírico con informantes y medir qué activaciones en concreto les provocan este tipo de vocablos.

En suma, las creaciones neológicas se enmarcan dentro de un contexto sociohistórico que es el que facilita la interpretación del significado. Estas, en ocasiones, son planificadas para activar ciertos espacios mentales que creen respuestas negativas emocionales en los lectores. En español hemos constatado como los elementos del euskera son utilizados con frecuencia por personas y medios de comunicación de tendencia conservadora y de derechas para formar eductos tendenciosos. Queda claro pues que las palabras no son inocentes y que estas no se comprenden sin los hechos históricos que las arropan. Es por ello por lo que más estudios a medio camino entre la pragmática, el análisis del discurso y la morfología son necesarios.

\section{REFERENCIAS}

ADAMO, G. \& DELLA VALLE, V. (2006): 2006 parole nuove, $\mathrm{Mi}$ lano: Sperling \& Kupfer Editori.

ALVAR EZQUERRA, M. (2003): Nuevo diccionario de voces de uso actual, Madrid: ArcoLibros.

CABRÉ, M. T. (1993): La terminología: teoria, metodologia y aplicaciones. Barcelona: Empuries.

CASAS OLCOZ, A. M. (2020): "Txakurra, cipayo, ekintza y talde. La construcción del discurso ideológico del miembro de ETA en Patria, de Fernando Aramburu", Tonos digital, 38, pp. $1-22$.

CASTELLS, M. (2009): Comunicación $y$ poder, Madrid: Alianza Editorial.

CASTILLO CARBALLO, $\mathrm{M}^{\mathrm{a}}$. A., GARCÍA PLATERO, J. M. \& MEDINA GUERRA, A. M ${ }^{a}$. (1993): "Los neologismos por derivación y composición en el lenguaje periodístico", Verba, 20, pp. 413- 423.

CUENCA, M. J. \& HILFERTY J.
(1999): Introducción a la lingüistica cognitiva. Barcelona: Ariel.

DOPPAGNE, A. (1971): "La neologie dans les communication de masse", La Banque des mots, 1, pp. 13-22.

EQUIPO PEDAGÓGICO (2012): Diccionario clave. Lengua Española. Madrid: SM.

ESTORNELL PONS, M. (2009): Neologismos en la prensa: criterios para reconocer y caracterizar las unidades neológicas. Valencia: Universitat de Valencia.

FAIRCLOUGH, N. (2013): Critical Discourse Analysis. The Critical Study of Language, Nueva York: Routledge.

FAITELSON-WEISER, S. (1993): "Sufijación y derivación sufijal: sentido y forma", Varela Ortega, S. (ed.), La formación de palabras. Madrid: Taurus, pp. 119-161.

FAUCONNIER, G. (1985): Mental spaces: Aspects of meaning 
construction in natural language, Cambridge: Cambridge University Press.

FAUCONNIER, G. (1997): Mappings in Thought and Language, Cambridge: Cambridge University Press.

FAUCONNIER, G. \& TURNER, M. (2002): The Way We Think, New York: Basic Books.

FERNÁNDEZ DE GOBEO DÍAZ DE DURANA, N. (2014): "La presencia del euskera en el español: los vasquismos en el diccionario académico", ELUA, 28, pp. 215-233.

FERNANDEZ SEVILLA, J. (1982): Neología y neologismo en el español contemporáneo. Granada: Don Quijote.

GARCÍA PLATERO, J. M. (1999): "Los medios de comunicación ante la neología", M. Alvar Ezquerra y G. Corpas Pastor (coords.): Léxico y voces del español. Málaga: Universidad de Málaga.

GARCIA PLATERO, J. M. (2006): "El léxico de los medios de comunicación", E-excellence, www. liceus.com, pp. 1-17.

GUERRERO SALAZAR, S. (2018): "Neologismos tendenciosos en los titulares deportivos de la prensa española". Recuperado de https://cineo2018.sciencesconf.org/172478/document.

GUILBERT, L. (1975): La creativite lexicale, Paris: Larousse.

HERNÁNDEZ, H. (2008): "Actuales procedimientos imaginativos de renovación léxica", F. Vilches Vivancos (coord.), Creación neológica y la sociedad de la información, Madrid: Universidad Rey Juan Carlos.

IGARTUA, J. J., MUÑIZ, C. \& CHENG, L. (2005): "La inmigración en la prensa española. Aportaciones empíricas y metodológicas desde la teoría del encuad- re noticioso", Migraciones, 17, 143-181.

LAVALE ORTIZ, R. (2020): "El sentimiento de novedad en la identificación de neologismos: configuración de corpus y criterios para su clasificación", $\mathrm{R}$. Lavale Ortiz (ed.), Cognitivismo y neología: estudios teóricos y aplicados, Madrid: Iberoamericana.

LLOPART-SAUMELL, E. (2016): "La funció dels neologismes: revisió de la dicotomia neologisme denominatiu i neologisme estilístic". Tesis doctoral. Universitat Pompeu Fabra. Recuperada de https://www.tdx.cat/ handle $/ 10803 / 398142$ \#page $=1$.

LÓPEZ DE LA CERDA \& DEL VALLE, C. (2007): "Ideología, medios de comunicación y género", Comunicación e cidadanía, 1 , 101-106.

LOPRIORE, L. \& FURIASSI, C. (2015): "The influence of English and French on the Italian language of fashion: Focus on false Anglicisms and false Gallicisms", Pseudo-English: Studies on False Anglicisms in Europe, 9, pp. 197.

LORENZO, E. (1996): Anglicismos hispánicos, Madrid: Gredos.

MANCERA RUEDA, A. (2009): "Oralización' de la prensa española: la columna periodistica", Berna: Peter Lang.

MARSH, D. (2018): "Foreword", Porta Linguarum, 3, pp. 5-10.

MÉNDEZ SANTOS, M. C. (2011a): Los neologismos morfológicos del español en el lenguaje de la prensa. Estudio de la lexicogénesis del español a través de la prensa del español actual, Saarbrucken: Editorial Académica Española.

MÉNDEZ SANTOS, M. C. (2011b): "Sobre -gate. Origen, significa- 
do y comportamiento morfológico", Cuadernos del Instituto de Historia de la Lengua, 6, pp. 23-44.

MÉNDEZ SANTOS, M. C. (2012): "Sobre -landia. Origen, significado y comportamiento morfológico", Signo y seña, 22, pp. 281289.

MÉNDEZ SANTOS, M. C. \& ÁlVAREZ MELLADO, E. (2021): "Origen y comportamiento del formante -exit en español", Tonos digital: Revista de estudios filológicos, 40, pp. 1-18.

MOLINER, M. (2007): Diccionario de usodelespañol.Madrid:Gredos.

MOLINER, M. (2002): Diccionario de usodelespañol.Madrid:Gredos.

PHARIES, D. (2002): Diccionario etimológico de los sufijos españoles y de otros elementos finales, Madrid: Gredos.

PRAT SABATER, M. (2019): "El sufijo -ing en español y catalán: análisis contrastivo desde la perspectiva lexicográfica", Revista de Investigación Lingüistica, 22, pp. 369-396.

RAINER, F. (1999): "La derivación adjetival", Bosque, I. y Demonte, V. (dir.), Gramática descriptiva del español, Madrid: Espasa, pp.4595-4643.

RAMOS, G., ANDRÉS, O. \& SECO, M. (1999): Diccionario del español actual, Madrid: Aguilar.

REAL ACADEMIA ESPAÑOLA: Banco de datos (CREA) [en línea]. Corpus de referencia del espanol actual. <http://www.rae. es $>[01 / 08 / 2020]$.

REAL ACADEMIA ESPAÑOLA (2019): Diccionario de la lengua española, Recuperado de https:// dle.rae.es /

REKALDE, Á. (2003): "Violencia, juventud vasca y medios de comunicación social", Estudios sobre el Mensaje Periodistico,
9, pp. 281-300.

REUTERS (2021): Reuters Institute Digital News report 2021. 10th edition. Recuperado de https://reutersinstitute.politics.ox.ac.uk/sites/default/ files/2021-06/Digital_News_ Report_2021_FINAL.pdf.

RODRÍGUEZ GUTIÉRREZ, Y. V. (2018): "Anglicismos y galicismos en artículos periodísticos sobre moda", Estudios de lingüística inglesa aplicada, 18, pp. 137-156.

ROMERO GUALDA, M. V. (1999): "Neologismo y medios de comunicación", González Calvo, J. M. et al. (eds.), El neologismo, Cáceres: Universidad de Extremadura, pp. 67-96.

ROMERO GUALDA, M. V. (2000): El Español en los medios de comunicación, Madrid: ArcoLibros.

RUBIO ESTEBAN, M. M. (2018): "El vocabulario político como adaequatio entre la ideología y la realidad", Lanza digital, 27/08/2018.

RUIZ GURILLO, L. (2019): Humor de género. Del texto a la identidad en español, Iberoamericana Vervuert.

SALA FERNÁNDEZ, T. (2005): "Lenguaje e ideología: un ejemplo periodístico", Espéculo. Revista de estudios literarios, 30.

SECO, M. (2007): "El relevo de las palabras", Campos Souto, M. et al. (coord.): El nuevo léxico, A Coruña: Universidade de A Coruña, pp. 9-25.

TERUEL RODRÍGUEZ， L. (2012): "El posicionamiento editorial de la prensa española sobre la polarización política", Capdevila, A. et al. (eds), Estudios de Comunicación política, Madrid: Tecnos, pp. 169-191. VAN DIJK, T. (1980a): "Algunas notas sobre la ideología y la te- 
oria del discurso", Semiosis, 5, pp. 37-53.

VAN DIJK, T. (1980b): Texto y contexto: Semántica y pragmática del discurso, Madrid: Cátedra.

VAN DIJK, T. (1993): "El poder i els mitjans de comunicación", Periodistica, 6, pp. 11-38.

VAN DIJK, T. (1997): Racismo y análisis crítico de los medios, Barcelona: Paidós Comunicación.

VAN DIJK, T. (1999): "El análisis crítico del discurso", Anthropos, 186, pp. 23-36.

VAN DIJK, T. (2005): "Ideología y análisis del discurso", Utopía y praxis latinoamericana: revista internacionaldefilosofiaiberoamericana y teoría, 29, pp. 9-36.
VEGA MORENO, E. (2016): “El préstamo como procedimiento de creación neológica", Pragmalingüistica, 24, pp. 281-292.

VEGA MORENO, E. \& LLOPART SAUMELL, E. (2017): "Delimitación de los conceptos de novedad y neologicidad", RILCE, 33(3), pp. 1416-1451.

VERES, L. (2002): "El signo perverso: sobre lenguaje, terrorismo y práctica periodística", Revista Latina de Comunicación Social, 52, pp. 288-298. 